\title{
Surgical oncology - at the crossroads
}

\author{
R. A. Badwe $\cdot$ C. S. Pramesh
}

Surgical oncology has seen dramatic changes in the past two decades. When I began my training in oncology, I remember being awestruck by the magnitude of procedures performed by the doyens of surgery of the time. As a young, impressionable surgeon fresh out of general surgical training, these radical operations reinforced in me, the caricature of the larger than life 'gladiator' waging a heroic battle against cancer. Today, that surgeon would be a caricature for all the wrong reasons. Gone are the days when 'more was better'. Conservative surgery, with minimal impact on quality of life, has become the norm. Breast conservative surgery has made rapid inroads and more than two-thirds of women with early breast cancer can potentially be spared the physical and emotional trauma of a mastectomy. Limb conserving surgery has replaced amputations in patients with osteogenic sarcoma; larynx-preserving treatment options have become a viable alternative to laryngectomy. The reasons for this shift in philosophy has resulted from a combination of various factors: effective chemotherapeutic agents, improved radiation techniques, better appreciation of tumor biology, results of randomized trials and an increased awareness of quality of life issues [1].

Another major change has been the way Evidence Based Medicine (EBM) has been readily embraced by oncologists - both surgical and non-surgical. The era of the braggart surgeon deriding the clinician-scientist for pursuing clinical research is firmly in the past. A number of landmark clinical trials in cancer have been conceptualized and carried out by surgeons [2]. These trials have gone beyond the confines of surgery and have straddled the entire spectrum of cancer treatment. Many of these trials have convincingly shattered long-held myths and established new paradigms. We need to leverage the primary role we play as surgeons in the multi disciplinary team (MDT) to lead the team towards identifying specific problems, discuss and debate potential

R. A. Badwe $\cdot$ C. S. Pramesh

Department of Surgical Oncology

Tata Memorial Hospital

Parel, Mumbai - 400012, India

R. A. Badwe $(\bowtie)$

E-mail: badwera@tmc.gov.in ways of addressing them, and finally provide solutions to these problems. The Calman Hine report [3] recognized that "the presence of appropriately trained site-specialized consultant surgeons in the Cancer Unit ... (is) fundamental" while leaving the role of the non-surgical oncologist more fluid and ambiguous.

Technological improvement has propelled several recent advances in cancer surgery. Minimally invasive surgery (MIS) found delayed acceptance amongst surgical oncologists, primarily fueled by the fear of not being able to perform radical surgery as well as with open techniques. The situation has changed now, with MIS being adopted readily by thoracic, gastrointestinal, gynecologic, urologic and head and neck cancer surgeons. Theoretically, the advantages of MIS are many; however, none of these advantages have been conclusively proven, and like most other surgical 'advances', MIS has been accepted without really being tested. With increasing investments being made in healthcare, especially in the private sector, a similar situation may happen with robotic surgery. My personal view is that the superiority of any new innovation or advance needs to be established before it is adopted by our community; and if that means testing new technology, so be it.

Cutting-edge technological advances notwithstanding, the biggest challenge our country faces is the lack of uniformity in delivery of healthcare. Considering the size of our country and its population, there is a gross shortage of specialized centres providing optimum cancer care. Several studies $[4,5]$ have conclusively shown that both short term and long term outcomes of cancer surgery depend upon individual surgeon and hospital volume. A review [6] of 88 published papers found that $77 \%$ of the studies found a positive correlation between volume and outcome. This is especially true for complex surgeries like esophageal and pancreatic resections where the difference in postoperative mortality between low and high volume centres is almost six-fold. Long term survival has also been found to be superior for patients operated by high volume surgeons even for relatively less complex surgeries like mastectomy and breast conservation. This is attributed to better coordination of overall care and more appropriate use of neoadjuvant and adjuvant therapy. 
There are two theories to explain this difference in outcomes between high and low volume centres and surgeons. The first, and the more intuitively appealing explanation, is that performance of surgeons and centres improve with higher volumes and the resultant experience. The second is that better-known surgeons and institutes attract referrals from various (smaller) centres and this adds to their operative volumes. This appears to be a classic situation of which came first - the chicken or the egg. Whatever the reason, there is enough evidence in literature now to make strong recommendations for treating patients with cancer in high volume centres. This is not to state that patients should only be treated in existing tertiary referral hospitals, nor does it mean the death of the primary (general) surgeon. What this means is that the 'smaller' centres need to be upgraded with adequate infrastructure and manpower to become high volume centres. Several such centres, each with its own niche area of specialization would be necessary to fulfill the unmet needs of the country's population.

Training in surgical oncology is another area which concerns me - few medical colleges (where the large majority of our young surgeons are trained) have surgical oncology as a separate specialty. With the occasional cancer surgery being performed in general surgical units, the surgical postgraduate has restricted exposure to major cancer resections. As a consequence, surgical oncology as a specialty fails to arouse interest in the young surgeon who decides to sub specialize. There is an urgent need to either rotate general surgical residents through specialized oncology centres or start departments of surgical oncology in medical colleges where they could be trained.

Dramatic changes have occurred in the specialty of surgical oncology since its birth; and yet, many more changes lie ahead of us. To truly grow, we need, as a specialty, to flow with, and not be swept away, by these winds of change. I believe that we should think of ourselves not merely as surgical technicians, but more as oncologists in a multidisciplinary team. This might go against the 'macho' image we have held for several decades as the dynamic, arrogant 'king' of an action-packed operating room; to realize that we could have more of an impact by being a cunning strategist in this war against cancer, rather than just a skilled technician priding ourselves in our abilities to remove the most advanced tumors - to win by subtlety rather than brute force. This change, at an individual level, will not be easy. We have been trained, for years, to operate, and operate well; to take pride in our technical skills, and rightfully so. To be told that these skills should take a backseat to a more refined role - that of an oncologist, working with non-surgical colleagues, to improve outcomes by utilizing every resource at our disposal, many of them not involving surgery - requires extreme maturity. The choice is ours - and the opportunity to lead the fight against cancer lies in our hands.

\section{References}

1. Lopez MJ (2005) The evolution of radical cancer surgery. Surg Oncol Clin N Am 14:xiii-xv

2. Yopp AC, DeMatteo RP, Preface (2010) Randomized controlled trials. Surg Oncol Clin N Am 19:xv-xvii

3. Calman K, Hine D. A policy framework for commissioning cancer services. http://www.dh.gov.uk/prod_consum_dh/ groups/dh_digitalassets/@dh/@en/documents/digitalasset/ dh_4014366.pdf (accessed 4, December 2009)

4. Begg CB, Cramer LD, Hoskins WJ, Brennan MF (1998) Impact of hospital volume on operative mortality for major cancer surgery. JAMA 280:1747-1751

5. Birkmeyer J, Siewers A, Fudoyson E, et al. (2002) Hospital volume and surgical mortality in the United States. N Eng J Med 346:1128-1137

6. Halm EA, Lee C, Chassin MR (2002) Is volume related to outcome in health care? A systematic review and methodological critique of the literature. Ann Intern Med 137:511-520 